\title{
Primary Percutaneous Coronary Intervention vs Conservative Treatment for Acute ST Elevation Myocardial Infarction Short- and Long-Term Follow-up According to Disease Severity
}

\author{
Ryo Koyanagi, MD; Nobuhisa Hagiwara, MD; Hiroshi Kasanuki, MD; \\ Yukio Tsurumi, MD; Hiroshi Ogawa, MD on behalf of \\ the HIJAMI investigators
}

\begin{abstract}
Background Because there is insufficient evidence to support primary percutaneous coronary intervention (PPCI) as the treatment of acute myocardial infarction (AMI), this study elucidated the efficacy of PPCI according to disease severity.

Methods and Results Between January 1999 and June 2001, 3,021 AMI patients were registered at Tokyo Women's Medical University and 17 affiliated institutions. Of these, 1,994 patients with ST-elevation AMI were admitted within $12 \mathrm{~h}$ of onset. PPCI was performed in 1,143 and 294 were treated conservatively. The 1,437 patients were grouped according to Thrombolysis In Myocardial Infarction-risk score: PPCI was performed in $59.5 \%$ of the low-risk group, $61.8 \%$ of the moderate-risk group, and $56.2 \%$ of the high-risk group. Cardiac death was the primary outcome. In the low-risk group, no significant differences were observed between PPCI and conservative therapy for 30-day and long-term cardiac mortality rates. In the moderate-risk group, the 30-day cardiac mortality rate for PPCI was significantly lower; however, no significant intergroup differences were observed for long-term cardiac mortality. In the high-risk group, 30-day and long-term cardiac mortality for PPCI were significantly more favourable than for conservative therapy $(\mathrm{p}<0.001$ and $\mathrm{p}=0.0032$, respectively).

Conclusions Although PPCI strongly correlated with low short- and long-term cardiac mortality rates in highrisk AMI patients, no similar correlation was found in low-risk patients. (Circ J 2008; 72: 1391-1396)
\end{abstract}

Key Words: Acute myocardial infarction; Percutaneous coronary intervention; Prognosis; Reperfusion therapy; TIMI-risk score

$\mathbf{I}$ $\mathrm{n}$ recent years, primary percutaneous coronary intervention (PPCI) has gradually emerged as the preferred treatment strategy for ST-elevation myocardial infarction (STEMI) 1,2 In particular, the usefulness of PPCI for acute myocardial infarction (AMI) resulting in cardiogenic shock has been recognised? In the treatment of STEMI, PPCI is associated with favourable vital prognosis, and current therapeutic guidelines for STEMI recommend PPCI whenever feasible5,6 Numerous randomized studies and meta-analyses have demonstrated the superiority of PPCI over thrombolytic therapy for AMI. However, in recent randomized trials, investigators have demonstrated a lack of cost-effectiveness for PPCI in some cases, as compared with thrombolytic therapy 7,8 To the best of our knowledge, no randomized comparative studies have assessed the use-

(Received August 23, 2007; revised manuscript received April 8, 2008; accepted April 16, 2008)

Department of Cardiology, The Heart Institute of Japan, Tokyo Women's Medical University, Tokyo, Japan

Mailing address: Nobuhisa Hagiwara, MD, Department of Cardiology, The Heart Institute of Japan, Tokyo Women's Medical University, 8-1 Kawada-cho, Shinjuku-ku, Tokyo 162-8666, Japan. E-mail: mhagi@hij.twmu.ac.jp

All rights are reserved to the Japanese Circulation Society. For permissions, please e-mail: cj@j-circ.or.jp fulness of PPCI and conservative therapy in the treatment of AMI. Whether percutaneous coronary intervention (PCI) is essential in all AMI patients thus remains unclear.

To elucidate the characteristics of AMI in the Japanese population, we conducted a prospective cohort study to investigate therapeutic modalities and prognosis of AMI at the Department of Cardiology of Tokyo Women's Medical University (The Heart Institute of Japan, Cardiology) and its 17 affiliated institutions, and report our findings here.

\section{Methods}

The protocol was approved by the Ethics Committee of Tokyo Women's Medical University.

\section{Study Population}

The study population was drawn from a registered prospective Japanese multicenter observational cohort, the Heart Institute of Japan Acute Myocardial Infarction (HIJAMI) registry9,10 Briefly, 3,021 consecutive patients with AMI admitted to 17 Japanese hospitals were registered from January 1999 to June 2001. Among these, eligible patients were those over 20 years old with chest pain or ECG changes typical of AMI accompanied by an increase in cardiac enzymes to at least twice the upper limit of the normal 


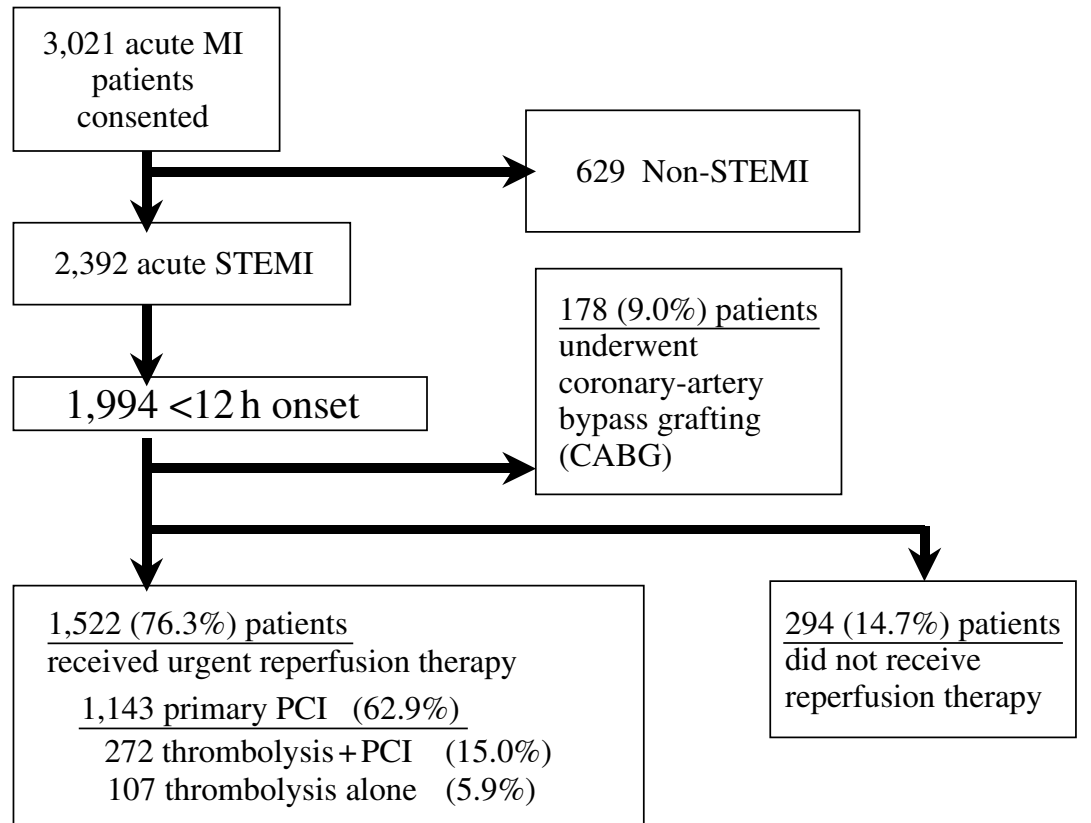

Fig 1. Flow of patients in the Heart Institute of Japan Acute Myocardial Infarction (HIJAMI) Registry. MI, myocardial infarction; STEMI, ST-elevation myocardial infarction; PCI, percutaneous coronary intervention.

Table 1 Patient Characteristics in Relation to TIMI-Risk Scores

\begin{tabular}{|c|c|c|c|}
\hline TIMI-risk score & $\leq 3(n=455)$ & $4 \leq \leq 5(n=517)$ & $6 \leq(n=465)$ \\
\hline Age (years) & $56 \pm 9$ & $71 \pm 10$ & $75 \pm 9$ \\
\hline Women (\%) & $52(11 \%)$ & $172(33 \%)$ & $196(42 \%)$ \\
\hline \multicolumn{4}{|l|}{ Killip class $(\%)$} \\
\hline I & $451(99 \%)$ & $496(96 \%)$ & $232(50 \%)$ \\
\hline II & $4(1 \%)$ & $13(3 \%)$ & $80(17 \%)$ \\
\hline III & $0(0 \%)$ & $7(1 \%)$ & $48(10 \%)$ \\
\hline IV & $0(0 \%)$ & $1(0 \%)$ & $105(23 \%)$ \\
\hline Anterior MI & $186(41 \%)$ & $222(43 \%)$ & $309(66 \%)$ \\
\hline$Q$-wave $M I$ & $342(75 \%)$ & $398(77 \%)$ & $364(78 \%)$ \\
\hline \multicolumn{4}{|l|}{ Clinical history } \\
\hline Prior AP & $169(37 \%)$ & $194(38 \%)$ & $183(39 \%)$ \\
\hline Hypertension & $209(46 \%)$ & $273(53 \%)$ & $298(64 \%)$ \\
\hline Hyperlipidemia & $213(47 \%)$ & $176(34 \%)$ & $140(30 \%)$ \\
\hline Diabetes mellitus & $161(35 \%)$ & $174(34 \%)$ & $175(38 \%)$ \\
\hline Prior MI & $53(12 \%)$ & $62(12 \%)$ & $86(18 \%)$ \\
\hline Prior PCI & $37(8 \%)$ & $44(9 \%)$ & $35(8 \%)$ \\
\hline Prior $C A B G$ & $3(1 \%)$ & $6(1 \%)$ & $5(1 \%)$ \\
\hline $\operatorname{LVEF}(\%)$ & $54 \pm 11$ & $54 \pm 13$ & $50 \pm 13$ \\
\hline \multicolumn{4}{|l|}{ No. of diseased vessels } \\
\hline$\leq 1$ & $282(62 \%)$ & $297(57 \%)$ & $215(46 \%)$ \\
\hline$\geq 2$ & $144(32 \%)$ & $144(28 \%)$ & $163(35 \%)$ \\
\hline Peak $C K(I U / m l)^{*}$ & $2,681[1,405-4,853]$ & $2,388[1,195-4,379]$ & $2,699[1,258-4,894]$ \\
\hline$L D L-C(m g / d l)$ & $128 \pm 38$ & $118 \pm 35$ & $118 \pm 37$ \\
\hline$C R P(\mathrm{mg} / \mathrm{dl})^{*}$ & $0.2[0.1-0.4]$ & $0.3[0.1-0.6]$ & $0.3[0.1-1.1]$ \\
\hline \multicolumn{4}{|l|}{ Medications at discharge ${ }^{* * *}$} \\
\hline ACEI or ARBs & $305(69 \%)$ & $310(65 \%)$ & $253(67 \%)$ \\
\hline$\beta$-blockers & $137(31 \%)$ & $162(34 \%)$ & $121(32 \%)$ \\
\hline Calcium-channel blockers & $116(26 \%)$ & $129(27 \%)$ & $114(30 \%)$ \\
\hline Nitrates & $239(54 \%)$ & $284(59 \%)$ & $238(63 \%)$ \\
\hline Aspirin & $406(92 \%)$ & $414(86 \%)$ & $334(89 \%)$ \\
\hline
\end{tabular}

Data are means $\pm S D$. *Values are medians; **among 30 days survivors.

TIMI, Thrombolysis In Myocardial Infarction; MI, myocardial infarction; AP, angina pectoris; $P C I$, percutaneous coronary intervention; $C A B G$, coronary artery bypass grafting; $L V E F$, left ventricular ejection fraction; $C K$, creatine kinase; $L D L-C$, low-density lipoprotein-cholesterol; CRP, C-reactive protein; ACEI, angiotensin-converting enzyme inhibitor; ARB, angiotensin-II receptor blocker.

value, and who were admitted within $48 \mathrm{~h}$ of onset. For each patient, a medical history was taken. Mean age was 69 years (range, 23-98 years) with a male preponderance $(70.7 \%$; 2,211 patients). As the HIJAMI study was meant for observational purposes only, treatment strategies such as pharma- cotherapy and early reperfusion treatment were determined at the discretion of physicians at each hospital.

We classified all patients registered in the HIJAMI study based on Thrombolysis In Myocardial Infarction (TIMI)risk scores ${ }^{12,13}$ in order to compare vital prognosis, and we 
Table 2 Breakdown by Therapeutic Modality

\begin{tabular}{|c|c|c|c|c|c|c|}
\hline \multirow[b]{2}{*}{ TIMI-risk score } & \multicolumn{2}{|c|}{$\leq 3$} & \multicolumn{2}{|c|}{$4 \leq \leq 5$} & \multicolumn{2}{|c|}{$6 \leq$} \\
\hline & $\begin{array}{c}\text { Conservative } \\
(n=72)\end{array}$ & $\begin{array}{c}P P C I \\
(n=383)\end{array}$ & $\begin{array}{c}\text { Conservative } \\
(n=119)\end{array}$ & $\begin{array}{c}\text { PPCI } \\
(n=398)\end{array}$ & $\begin{array}{c}\text { Conservative } \\
(n=103)\end{array}$ & $\begin{array}{c}P P C I \\
(n=362)\end{array}$ \\
\hline Age (years) & $59.7 \pm 10.0$ & $56.1 \pm 8.5$ & $77.1 \pm 9.8$ & $69.6 \pm 9.8$ & $78.7 \pm 9.4$ & $74.9 \pm 8.9$ \\
\hline Time of onset to admission $(h)^{*}$ & $2.6[1.7-5.3]$ & $2.0[1.2-3.5]$ & $2.8[1.8-4.3]$ & $2.8[1.6-4.7]$ & $2.6[1.2-5.4]$ & $3.3[2.0-5.2]$ \\
\hline \multicolumn{7}{|l|}{ Killip class $(\%)$} \\
\hline I & $71(98.6 \%)$ & $380(99.2 \%)$ & $112(94.1 \%)$ & $384(96.5 \%)$ & $23(22.3 \%)$ & $209(57.7 \%)$ \\
\hline II & $1(1.4 \%)$ & $3(0.8 \%)$ & $4(3.4 \%)$ & $9(2.3 \%)$ & $20(19.4 \%)$ & $60(16.6 \%)$ \\
\hline III & - & - & $2(1.7 \%)$ & $5(1.3 \%)$ & $27(26.2 \%)$ & $21(5.8 \%)$ \\
\hline IV & - & - & $1(0.8 \%)$ & - & $33(32.0 \%)$ & $72(19.9 \%)$ \\
\hline \multicolumn{7}{|l|}{ Clinical history } \\
\hline Hypertension & $35(48.6 \%)$ & $174(45.4 \%)$ & $63(52.9 \%)$ & $210(52.8 \%)$ & $75(72.8 \%)$ & $223(61.6 \%)$ \\
\hline Hyperlipidemia & $24(33.3 \%)$ & $189(49.3 \%)$ & $30(25.2 \%)$ & $146(36.7 \%)$ & $28(27.2 \%)$ & $112(30.9 \%)$ \\
\hline Diabetes mellitus & $18(25.0 \%)$ & $143(37.3 \%)$ & $42(35.3 \%)$ & $132(33.2 \%)$ & $45(43.7 \%)$ & $130(35.9 \%)$ \\
\hline Prior MI & $9(12.5 \%)$ & $44(11.5 \%)$ & $20(16.8 \%)$ & $42(10.6 \%)$ & $32(31.1 \%)$ & $54(14.9 \%)$ \\
\hline \multicolumn{7}{|l|}{ No. of diseased vessels } \\
\hline$\leq 1$ & $31(43.1 \%)$ & $251(65.5 \%)$ & $32(26.9 \%)$ & $265(66.6 \%)$ & $11(10.7 \%)$ & $205(56.7 \%)$ \\
\hline$\geq 2$ & $12(16.6 \%)$ & $132(34.5 \%)$ & $11(9.2 \%)$ & $133(33.4 \%)$ & $6(5.8 \%)$ & $157(43.3 \%)$ \\
\hline Unknown & $29(40.3 \%)$ & - & $76(63.9 \%)$ & - & $86(83.5 \%)$ & - \\
\hline Serum creatinine $(\mathrm{mg} / \mathrm{dl})$ & $0.9 \pm 0.3$ & $0.9 \pm 0.5$ & $1.1 \pm 1.2$ & $1.0 \pm 0.8$ & $1.4 \pm 1.2$ & $1.1 \pm 1.7$ \\
\hline POBA & - & $115(30.0 \%)$ & - & $129(32.4 \%)$ & - & $111(30.7 \%)$ \\
\hline$B M S$ & - & $268(70.0 \%)$ & - & $269(67.6 \%)$ & - & $251(69.3 \%)$ \\
\hline \multicolumn{7}{|l|}{ Medications at discharge } \\
\hline ACEI or ARBs & $41(58.6 \%)$ & $264(70.8 \%)$ & $46(46.0 \%)$ & $264(69.5 \%)$ & $36(56.3 \%)$ & $217(69.3 \%)$ \\
\hline$\beta$-blockers & $17(24.3 \%)$ & $120(32.2 \%)$ & $29(29.0 \%)$ & $133(35.0 \%)$ & $18(28.1 \%)$ & $103(32.9 \%)$ \\
\hline Calcium-channel blockers & $33(47.1 \%)$ & $83(22.3 \%)$ & $38(38.0 \%)$ & $91(23.9 \%)$ & $35(54.7 \%)$ & $79(25.2 \%)$ \\
\hline Nitrates & $50(71.4 \%)$ & $189(50.7 \%)$ & $81(81.0 \%)$ & $203(53.4 \%)$ & $57(89.1 \%)$ & $181(57.8 \%)$ \\
\hline Aspirin & $50(71.4 \%)$ & $356(95.4 \%)$ & $64(64.0 \%)$ & $350(92.1 \%)$ & $49(76.6 \%)$ & $285(91.1 \%)$ \\
\hline
\end{tabular}

PPCI, primary PCI; POBA, primary old balloon angioplasty; BMS, bare metal stent. Other abbreviations see in Table 1.

Table 3 Therapeutic Modality and Disease Severity

\begin{tabular}{lcccr}
\hline \hline TIMI-risk score & PCI alone, $n(\%)$ & Lytic alone, $n(\%)$ & Both, $n(\%)$ & Conservative, $n(\%)$ \\
\hline$\leq 3(n=644)$ & $383(59.5)$ & $59(9.2)$ & $130(20.2)$ & $72(11.2)$ \\
$4 \leq$ TIMI-risk score $\leq 5(n=643)$ & $398(61.8)$ & $36(5.6)$ & $90(14.0)$ & $119(18.5)$ \\
$6 \leq(n=529)$ & $362(56.2)$ & $12(1.9)$ & $52(8.1)$ & $103(16.0)$ \\
Total $(n=1,816)$ & $1,143(62.9)$ & $107(5.9)$ & $272(15.0)$ & $294(16.2)$ \\
\hline
\end{tabular}

Abbreviations see in Table 1.

then assessed the usefulness of PCI for AMI. Prognosis was assessed as of November 30, 2004. Mean duration of follow-up observation was 4.2 years, with a follow-up rate of $97 \%$.

\section{Definition of Endpoints}

The primary study outcome was cardiac death.

\section{Statistical Analysis}

Analyses were performed using SAS ver. 9.1 statistical software (SAS Institute, Cary, NC, USA). Data are presented as medians with interquartile ranges or frequencies. Cumulative probabilities of event-free curves were estimated using the Kaplan-Meier method. Cox proportional hazards models were used to evaluate the effects of primary reperfusion on the prognosis of AMI patients. The proportional hazards assumption was confirmed by the log survival function. The influences of profile, interaction and colinearity in the generalized linear model were examined using regression diagnostic analysis. Two-tailed p-values of less than 0.05 were considered to indicate statistically significant differences.

\section{Results}

A total of 3,021 consecutive AMI patients were registered. Of these, 1,994 had ST-elevation myocardial infarction within $12 \mathrm{~h}$ of onset and of them 178 who underwent coronary artery bypass grafting; the 379 in whom thrombolytic therapy was performed either alone or combined with PCI were excluded. Thus, 1,437 patients served as subjects (Fig 1). Patient baseline characteristics are summarized in Table 1 and the breakdown by therapeutic modality is summarized in Table 2.

The 1,437 patients were divided into 3 groups based on TIMI-risk score: low-risk group (TIMI-risk score $\leq 3$ ), moderate-risk group (TIMI-risk score 4 and 5) and high-risk group (TIMI-risk score $\geq 6$ ) (Table 3 ). For the entire patient population, 30-day cardiac mortality rates for PPCI and conservative therapy were $5.4 \%$ and $17.7 \%$, respectively.

A comparison between PPCI and conservative therapy for each group is presented below. Prognoses of patients treated with PPCI, as compared with conservative therapy, are shown in Table 4.

In the low-risk group, the 30-day cardiac mortality rate was compared between 383 patients who underwent PPCI and 72 patients treated conservatively. When compared with conservative therapy, no significant correlation was 

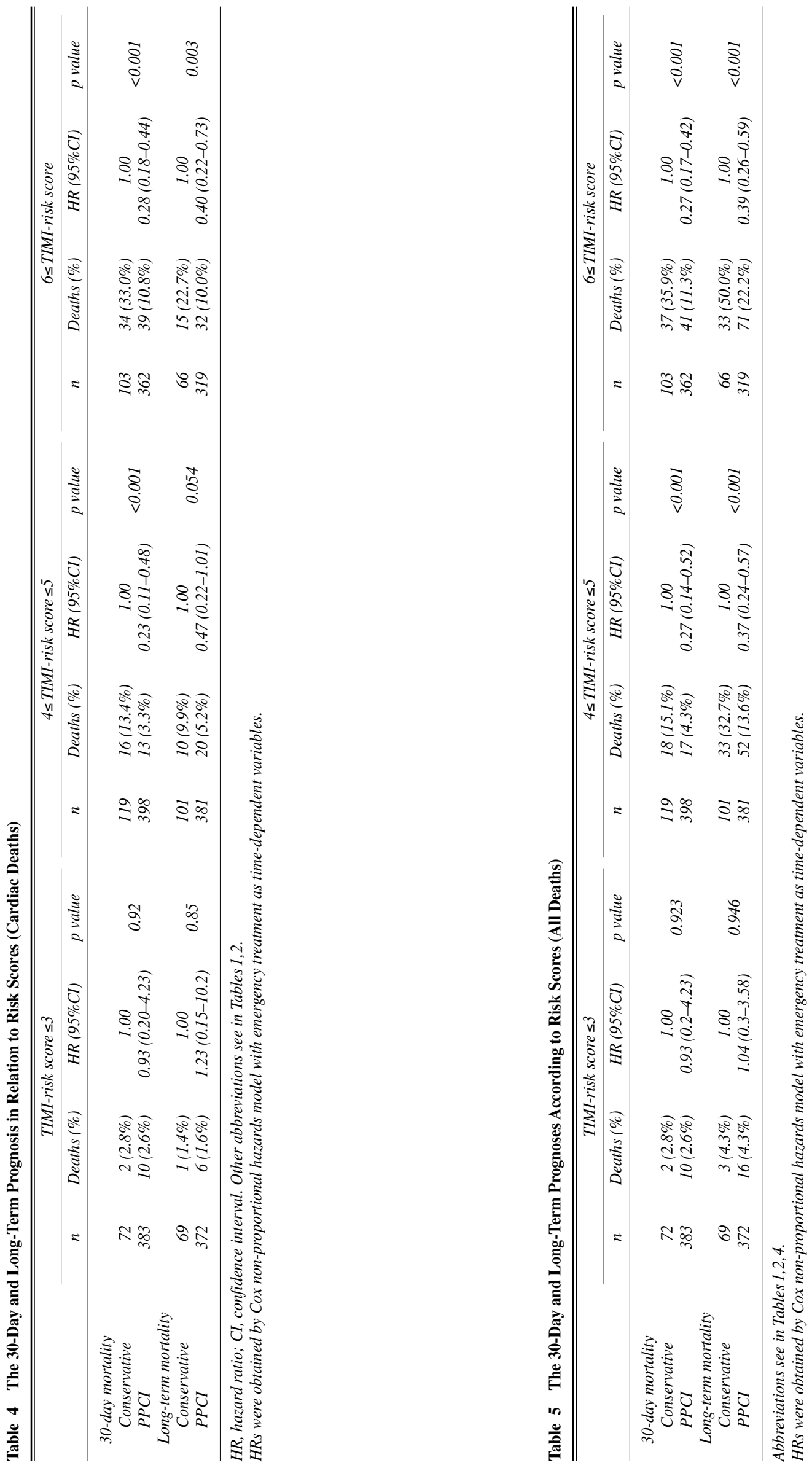
Low-risk group

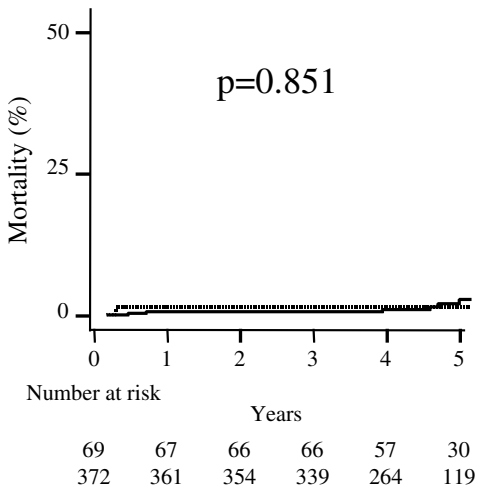

Moderate-risk group

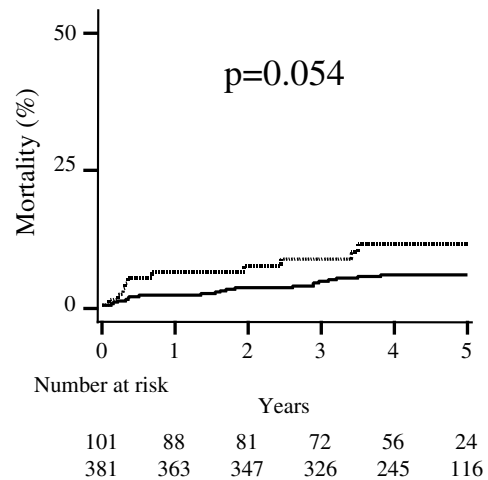

Conservative Group PPCI Group
High-risk group

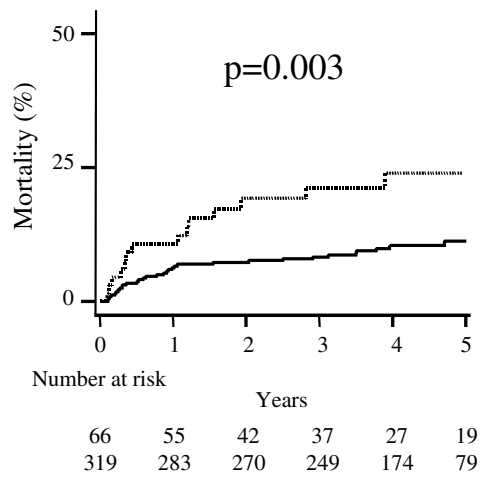

Fig 2. Kaplan-Meier curves for long-term cardiac mortality in relation to risk scores. Dotted line, conservative therapy; solid line, primary percutaneous coronary intervention.

seen between PPCI and improvement in 30-day cardiac mortality (hazard ratio (HR) $0.93,95 \%$ confidence interval (CI) $0.20-4.23, \mathrm{p}=0.93$ ). No significant correlation was seen between PPCI and improvement of long-term cardiac mortality (HR 1.23, 95\% CI 0.15-10.19, p=0.85) (Fig 2).

In the moderate-risk group, 30-day cardiac mortality rate was compared between 398 patients who underwent PPCI and 119 patients who underwent conservative therapy. When compared with conservative therapy, PPCI was significantly correlated with improved 30-day cardiac mortality (HR $0.23,95 \%$ CI $0.11-0.45$, p < 0.0001 ). However, no significant correlation was seen between PPCI and improvement of long-term cardiac mortality (HR 0.47, 95\% CI 0.22-1.01, p=0.054) (Fig 2).

In the high-risk group, 30-day cardiac mortality rate was compared between 362 patients who underwent PPCI and 103 patients who underwent conservative therapy. Compared with conservative therapy, significant correlations were seen between PPCI and short-term cardiac mortality rate (HR $0.27,95 \%$ CI $0.18-0.44, \mathrm{p}<0.0001)$, and between PPCI and long-term cardiac mortality rate (HR $0.40,95 \% \mathrm{CI}$ $0.22-0.73$, $\mathrm{p}=0.0032)($ Fig 2).

Similarly, no correlation was found between PPCI and total mortality in the low-risk AMI patients, although a significant correlation was found between these 2 factors in the moderate-risk and high-risk AMI patients (Table 5).

\section{Discussion}

In the present study, there were no significant differences in vital prognosis between conservative therapy and PPCI for low-risk ST-elevation AMI patients. On the other hand, in the moderate- and high-risk ST-elevation AMI patients, a significant correlation was seen between PPCI and the short-term cardiac mortality rate. Furthermore, in the high-risk ST-elevation AMI patients, a significant correlation was seen between PPCI and the long-term cardiac mortality rate. As previously reported in the DANAMI study, our study subjects were divided according to their TIMIrisk scores in order to determine the types of patients that respond to PCI?
In Western countries, thrombolytic therapy is the main reperfusion modality in the treatment of acute coronary syndrome (ACS). According to a recent report by the National Registry of Myocardial Infarction in the United States, ${ }^{14}$ PPCI monotherapy and thrombolytic treatment account for $7.3 \%$ and $20.8 \%$, respectively, of overall AMI treatments. In the GRACE registry, PPCI accounted for $52.7 \%$ of treatments for ACS 17 In contrast, in Japan PPCI accounts for approximately $60 \%$ of all treatments for AMI, 15,16 The following 2 factors are considered to influence the frequent use of PCI in Japan. First, most Japanese live in urban areas and have good access to medical facilities, which is also why t-PA treatment is not common in Japan (Table 3). Second, Japan has a universal health insurance system with fixed medical costs.

Grines et al compared the efficacy of primary PTCA and thrombolytic therapy in AMI patients and reported that when compared with thrombolytic therapy, primary PTCA significantly improved both short- and 6-month outcomes! 18 Widimsky et al performed PCI alone or thrombolytic therapy with or without PCI in AMI patients, and then assessed $\leq 30$-day mortality, re-infarction and stroke as the primary endpoints; their incidence of the primary endpoint was lowest in the PPCI group $1^{19}$ The usefulness of PCI for STelevation AMI has thus been established, but there is not a general consensus that PPCI is essential for all AMI patients and no randomized comparative studies have assessed the usefulness of PPCI vs conservative therapy in the treatment of AMI.

In the present study, thrombolytic therapy was performed in a very small number of patients and could not serve as a control for PPCI. In the DANAMI study? the mortality rate for thrombolytic therapy was $5.6 \%$ in the low-risk group and $36.2 \%$ in the high-risk group, which is comparable with the conservative therapy group used in the present study (Table 5). We therefore compared PPCI with conservative therapy. To demonstrate the usefulness of PPCI in patients with ST-elevation AMI, Thune et $\mathrm{al}^{7}$ compared PPCI with thrombolytic therapy based on disease severity and found no significant differences between the 2 treatments in the longterm mortality rate in low-risk AMI patients. However, in 
high-risk AMI patients, PCI significantly improved vital prognosis. The results of that study also support our findings. We thus believe that PPCI does not significantly improve prognosis in all patients with ST-elevated AMI.

\section{Study Limitations}

The present prospective cohort study was an observational study, not a randomized controlled trial, that randomly divided subjects into PCI and non-PCI groups. Some intergroup bias may thus have been present.

\section{Conclusions}

PPCI was actively performed in AMI patients. In highrisk AMI patients, it was strongly correlated with better outcomes than conservative treatment. Conversely, in lowrisk AMI patients, no correlation was identified between PPCI and vital prognosis. Beneficial effects of PPCI on both early and late outcomes were not observed in low-risk AMI patients when compared with conservative treatment. PPCI is thus not beneficial in all patients with STEMI. Aggressive approaches using PPCI should be performed for deteriorating AMI patients to improve their prognosis.

\section{Acknowledgments}

The authors thank the clinical research coordinators and Katsunori Shimada (STATZ Institute, Tokyo, Japan) for HIJAMI study administration and independent statistical analysis.

\section{References}

1. Weaver WD, Simes RJ, Betriu A, Grines CL, Zijlstra F, Garcia E, et al. Comparison of primary coronary angioplasty and intravenous thrombolytic therapy for acute myocardial infarction: A quantitative review. JAMA 1997; 278: 2093-2098.

2. Keeley EC, Boura JA, Grines CL. Primary angioplasty versus intravenous thrombolytic therapy for acute myocardial infarction: A quantitative review of 23 randomised trials. Lancet 2003; 361: $13-$ 20.

3. White HD, Assmann SF, Sanborn TA, Jacobs AK, Webb JG, Sleeper LA, et al. Comparison of percutaneous coronary intervention and coronary artery bypass grafting after acute myocardial infarction complicated by cardiogenic shock: Results from the Should We Emergently Revascularize Occluded Coronaries for Cardiogenic Shock (SHOCK) trial. Circulation 2005; 112: 1992-2001.

4. Kaul P, Armstrong PW, Chang WC, Naylor CD, Granger CB, Lee $\mathrm{KL}$, et al. Long-term mortality of patients with acute myocardial infarction in the United States and Canada: Comparison of patients enrolled in Global Utilization of Streptokinase and t-PA for Occluded Coronary Arteries (GUSTO)-I. Circulation 2004; 110: 1754-1760.

5. Antman EM, Anbe DT, Armstrong PW, Bates ER, Green LA, Hand M, et al; American College of Cardiology, American Heart Association, Canadian Cardiovascular Society. ACC/AHA guidelines for the management of patients with ST-elevation myocardial infarction: executive summary: A report of the American College of Cardiology/ American Heart Association Task Force on Practice Guidelines (Writing Committee to revise the 1999 guidelines for the management of patients with acute myocardial infarction). J Am Coll Cardiol 2004; 44: 671-719.

6. Krumholz HM, Anderson JL, Brooks NH, Fesmire FM, Lambrew $\mathrm{CT}$, Landrum MB, et al; American College of Cardiology/American Heart Association Task Force on Performance Measures, Writing Committee to Develop Performance Measures on ST-Elevation and Non-ST-Elevation Myocardial Infarction. ACC/AHA clinical performance measures for adults with ST-elevation and non-ST-elevation myocardial infarction: A report of the American College of Cardiology/American Heart Association Task Force on Performance Mea- sures (Writing Committee to Develop Performance Measures on STElevation and Non-ST-Elevation Myocardial Infarction). Circulation 2006; 113: 732-761.

7. Thune JJ, Hoefsten DE, Lindholm MG, Mortensen LS, Andersen HR, Nielsen TT, et al; Danish Multicenter Randomized Study on Fibrinolytic Therapy Versus Acute Coronary Angioplasty in Acute Myocardial Infarction (DANAMI)-2 Investigators. Simple risk stratification at admission to identify patients with reduced mortality from primary angioplasty. Circulation 2005; 112: 2017-2021.

8. Armstrong PW. A comparison of pharmacologic therapy with/without timely coronary intervention vs primary percutaneous intervention early after ST-elevation myocardial infarction: The WEST (Which Early ST-elevation myocardial infarction Therapy) study. Eur Heart $J$ 2006; 27: 1530-1538.

9. Kasanuki H, Honda T, Haze K, Sumiyoshi T, Horie T, Yagi M, et al; HIJAMI Investigators. A large-scale prospective cohort study on the current status of therapeutic modalities for acute myocardial infarction in Japan: Rationale and initial results of the HIJAMI Registry. Am Heart J 2005; 150: 411-418.

10. Yamaguchi J, Kasanuki H, Nagashima M, Koyanagi R, Ogawa H, Hagiwara N, et al; The Heart Institute of Japan, Cardiology (HIJC) Investigators. Serum creatinine on admission predicts long-term mortality in acute myocardial infarction patients undergoing successful primary angioplasty. Circ J 2007; 71: 1354-1359.

11. Koganei H, Kasanuki H, Ogawa H, Tsurumi Y. Association of glomerular filtration rate with unsuccessful primary percutaneous coronary intervention and subsequent mortality in patients with acute myocardial infarction. Circ J 2008; 72: 179-186.

12. Morrow DA, Antman EM, Charlesworth A, Cairns R, Murphy SA, de Lemos JA, et al. TIMI risk score for ST-elevation myocardial infarction: A convenient, bedside, clinical score for risk assessment at presentation: An intravenous nPA for treatment of infarcting myocardium early II trial substudy. Circulation 2000; 102: 2031-2037.

13. Morrow DA, Antman EM, Parsons L, de Lemos JA, Cannon CP, Giugliano RP, et al. Application of the TIMI risk score for ST-elevation MI in the National Registry of Myocardial Infarction 3. JAMA 2001; 286: 1356-1359.

14. Rogers WJ, Canto JG, Lambrew CT, Tiefenbrunn AJ, Kincaid B, Shoultz DA, et al. Temporal trends in the treatment of over 1.5 million patients with myocardial infarction in the U.S. from 1990 through 1999: The National Registry of Myocardial Infarction 1, 2 and 3. J Am Coll Cardiol 2000; 36: 2056-2063

15. Kinjo K, Sato H, Sakata Y, Nakatani D, Mizuno H, Shimizu M, et al; on Behalf of the Osaka Acute Coronary Insufficiency Study (OACIS) Group. Identification of uncomplicated patients with acute myocardial infarction undergoing percutaneous coronary intervention: Are these patients suitable for early discharge? Circ J 2005; 69: $1163-1169$.

16. Ishihara M, Kojima S, Sakamoto T, Asada Y, Tei C, Kimura K, et al; Japanese Acute Coronary Syndrome Study Investigators. Acute hyperglycaemia is associated with adverse outcome after acute myocardial infarction in the coronary intervention era. Am Heart $J$ 2005; 150: 814-820.

17. Fox KA, Philippe GS, Eagle KA, Goodman SG, Anderson FA, Granger CB, et al; GRACE Investigators. Decline in rate of death and heart failure in acute coronary syndoromes, 1999-2006. JAMA 2007; 297: 1892-1900.

18. Grines CL, Browne KF, Marco J, Rothbaum D, Stone GW, O'Keefe $\mathrm{J}$, et al, for The Primary Angioplasty in Myocardial Infarction Study Group. A comparison of immediate angioplasty with thrombolytic therapy for acute myocardial infarction: The Primary Angioplasty in Myocardial Infarction Study Group. N Engl J Med 1993; 328: 673 679.

19. Widimsky P, Budesinsky T, Vorac D, Groch L, Zelizko M, Aschermann M, et al; 'PRAGUE' Study Group Investigators. Long distance transport for primary angioplasty vs immediate thrombolysis in acute myocardial infarction: Final results of the randomized national multicentre trial (PRAGUE-2). Eur Heart J 2003; 24: $94-$ 104.

20. Menotti A, Puddu PE, Lanti M, Kromhout D, Blackburn H, Nissinen A. Twenty-five-year coronary mortality trends in the seven countries study using the accelerated failure time model. Eur J Epidemiol 2003; 18: $113-122$. 